\title{
Leia + Mulheres Restinga: projeto de incentivo à leitura de obras escritas por mulheres no IFRS
}

\section{Read + Women Restinga: a project to promote reading books written by women in IFRS}

\author{
Nathália Luísa Giraud Gasparini ${ }^{1}$ \\ Sandra Romero Silveira 2 \\ Lara Batista Barella ${ }^{3}$
}

\begin{abstract}
Resumo
O presente relato narra as ações do projeto de ensino Leia + Mulheres Restinga, realizado no campus Restinga do Instituto Federal do Rio Grande do Sul, financiado pelo Edital n 68/2019 de fomento interno a projetos de ensino dessa instituição, realizado entre setembro de 2020 e março de 2021. O projeto teve como objetivo fomentar a leitura de obras escritas por mulheres. As atividades consistiram em pesquisa, leitura e divulgação de obras literárias escritas por mulheres pelo grupo proponente e promoção de encontros abertos à comunidade para discussão, com o objetivo de auxiliar na formação de leitores/as e abordar obras e autoras que, na maioria das vezes, não são incluídas nos currículos dos cursos do campus. Ao longo deste relato, justificamos a necessidade de promover essas obras em nosso contexto escolar e narramos o percurso da criação do projeto. Depois, descrevemos as ações que promovemos, para, em sequência, detalhar como foram planejados e realizados os encontros de discussão das obras selecionadas. Por último, tecemos uma reflexão sobre como essas ações foram importantes tanto para a formação das estudantes bolsistas quanto para a comunidade escolar no sentido de promover o letramento literário.
\end{abstract}

Palavras-chave: Formação do leitor. Literatura escrita por mulheres. Letramento literário.

\begin{abstract}
The present report narrates the actions of the project Read + Women Restinga, developed in campus Restinga of the Federal Institute of Rio Grande do Sul and sponsored by public notice $n^{0} 68 / 2019$ for internal promotion of educational projects of this institution; the project was held between September of 2020 and March of 2021. The project aimed to promote reading books written by women. The activities consisted of researching, reading and disseminating literary works written by women and promoting meetings of discussion, with the objective of assisting the development of readers and addressing works and authors which, most of the times, are not included in the curricula of the courses. Throughout this report, we justify the need to promote these books in our school and describe the path of the creation of the project. Then, we list the actions we promoted and describe how the meetings to debate the selected works were planned and held. Finally, we reflect on how these actions were important for the training of scholarship students as well as for the school community in order to promote literary literacy.
\end{abstract}

Keywords: Reader development. Literature written by women. Literary literacy.

1 Mestra em Estudos da Linguagem. Instituto Federal de Educação, Ciência e Tecnologia do Rio Grande do Sul, Porto Alegre, RS, Brasil. Orcid: https://orcid.org/0000-0003-3666-0134. E-mail: nathalia.gasparini@restinga.ifrs.edu.br

2 Acadêmica da Licenciatura em Letras - Português e Espanhol. Instituto Federal de Educação, Ciência e Tecnologia do Rio Grande do Sul, Porto Alegre, RS, Brasil. Orcid: https://orcid.org/0000-0002-3199-3119.E-mail: 10150119@restinga.ifrs.edu.br 3 Estudante do Curso Técnico em Lazer integrado ao Ensino Médio. Instituto Federal de Educação, Ciência e Tecnologia do Rio Grande do Sul, Rio Grande do Sul, Porto Alegre, RS, Brasil. Orcid: https://orcid.org/0000-0002-4962-3263. E-mail: larafelinos@gmail.com

LínguaTec, Instituto Federal de Educação, Ciência e Tecnologia do Rio Grande do Sul, Bento Gonçalves v. 6, n. 1, p. 84-99, jun. 2021. 


\section{Introdução}

O cânone literário ensinado por meio da historiografia nos currículos escolares representa uma série de escolhas histórica e socialmente situadas que, portanto, exclui uma diversidade de sujeitos, obras e temáticas. Recentemente, vimos diversos movimentos de renovação da tradição; um exemplo emblemático foi a inclusão dos estudos de Úrsula, de Maria Firmina dos Reis, primeiro romance do período do Romantismo Brasileiro, nos currículos e provas de vestibular. Sendo a autora uma mulher negra, ficam evidentes os critérios sociais utilizados para incluir ou excluir obras do que se estabelece como o cânone da Literatura Brasileira (ROSA, 2020) e que, por isso, acabam tendo lugar de destaque nos conteúdos programáticos para o ensino no contexto escolar, sobretudo no Ensino Médio. Deixa ver, ainda, que esse processo de inclusão ou exclusão vem sendo ressignificado a partir de outras visões de mundo, práticas de leitura e formas de ver a identidade brasileira e a experiência humana, conforme os estudos decoloniais vêm apontando (MEDEIROS, 2018). Embora seja importante dar a conhecer as produções de literatura em língua portuguesa ao longo da história, é notável que algumas práticas curriculares acabam encerrando seus objetivos na promoção da produção literária escrita por homens, brancos e da elite cultural que, afinal, representam o conteúdo dos manuais de literatura. Por isso, práticas de ensino que proporcionem outras experiências com a literatura têm sido cada vez mais impulsionadas nos contextos escolares.

Buscando diversificar as experiências de leitura dos estudantes do campus Restinga do Instituto Federal do Rio Grande do Sul (IFRS), organizamos o Grupo de Estudo, Pesquisa, Discussão e Divulgação Leia + Mulheres Restinga. Trata-se de um projeto de ensino, financiado pela instituição através de bolsas para as estudantes envolvidas na organização, cujo objetivo principal é promover a leitura literária de obras escritas por mulheres através de ações de ensino para a comunidade escolar, atuando para ampliar as possibilidades de abordagens à literatura em relação àquelas prescritas nos currículos de nossos cursos.

A história desse projeto remonta a uma iniciativa autônoma, no campus Ibirubá do IFRS, resultado de conversas e parcerias entre professores e professoras de Língua Portuguesa e Literatura, que notaram a rigidez do currículo em relação às leituras e obras priorizadas. 0 grupo buscou inspiração na campanha \#readwoman2014, impulsionada pela escritora britânica Joanna Walsh, cuja proposta consistia em ler livros de autoria feminina e colocar em discussão essas obras. Como resultado, em 2015, clubes de leitura chamados Leia Mulheres começaram a se organizar no Brasil em bibliotecas e livrarias, realizando encontros mensais para discussão de obras escolhidas pelas frequentadoras, com 
mediadoras que promoviam essas reuniões (SANTOS, 2019). Hoje, esses grupos já estão presentes em cerca de 160 cidades brasileiras, o que representa um caso de sucesso na promoção da leitura em contextos não-escolares (ROSSI; BRIGNOL, 2020). A partir dessa referência, o grupo de professores daquele campus propôs, então, encontros mensais na hora do almoço para discutir obras curtas (contos e coletâneas de poemas) escritas por mulheres, sobretudo com estudantes do Ensino Médio. Os encontros tiveram uma ótima adesão de estudantes.

Uma das professoras organizadoras desses encontros passou a trabalhar no campus Restinga e, junto a uma estudante do Ensino Médio do curso de Lazer, começou a instigar estudantes e servidores/as a escreverem resenhas e dicas de livros escritos por mulheres para serem divulgados nas redes sociais. Foi satisfatória a adesão da comunidade escolar e, após o projeto ter sido registrado em edital específico para ações de ensino, formou-se o grupo que aqui relata as atividades realizadas. $\mathrm{Na}$ nossa instituição, projetos de ensino são ações não-curriculares propostas por servidores, que os executam em parceria com estudantes, com o objetivo de melhorar os processos de ensinoaprendizagem, desencadear processos de inovação na prática pedagógica, contribuir para 0 aprimoramento da qualidade dos cursos e estimular práticas que ampliem as vivências dos estudantes além daquelas previstas nos Projetos Pedagógicos dos Cursos. Assim, elaboramos nosso projeto a partir dos seguintes objetivos: fomentar a leitura de obras escritas por mulheres e ampliar as experiências de leitura dos estudantes para além das práticas curriculares de ensino de Língua e Literatura; envolver a comunidade escolar e acadêmica do IFRS nos recentes debates mundiais sobre cânone e literatura escrita por mulheres; pesquisar autoras contemporâneas de relevância nacional e internacional; divulgar leituras nesse escopo que já são realizadas pela comunidade para criar uma rede de recomendações literárias; e realizar encontros de discussão de obras selecionadas, incentivando a leitura e desenvolvendo, em conjunto, ferramentas de interpretação e análise.

Neste relato, expomos nossa visão acerca da necessidade de promover, na escola, a leitura de obras escritas por mulheres e narramos as atividades realizadas de setembro de 2020 a março de 2021 pelo grupo, composto por uma estudante do Ensino Médio, duas acadêmicas de Licenciatura em Letras e a coordenadora do projeto, tendo como público-alvo, inicialmente, a comunidade escolar do campus Restinga do IFRS. De forma detalhada, lançamos um olhar para os encontros de discussão de obras, que identificamos como eventos de promoção do letramento literário. Por fim, são tecidas considerações sobre a avaliação das atividades pelo grupo. 


\section{Por que ler mais mulheres no contexto escolar?}

Partimos do pressuposto de que a literatura é um instrumento de instrução e educação, como equipamento intelectual e afetivo, uma vez que "confirma e nega, propõe e denuncia, apoia e combate, fornecendo a possibilidade de vivermos dialeticamente os problemas" (CANDIDO, 1995, p. 113). Desse modo, é um mundo em si mesmo e, ao mesmo tempo, permite outras formas de ler o mundo. No entanto, é fato que a historiografia literária ocidental selecionou, tanto em termos de produtores quanto de representações, a leitura de mundo das masculinidades brancas socialmente privilegiadas. De acordo com Bourdieu (2005), a produção cultural de modo geral é sede de lutas e conflitos e, através da chancela da definição de escritor, delimita-se a população daqueles que têm direito (ou não) a participar da luta por essa definição. Essa delimitação reflete e refrata uma estrutura classista, desigual e patriarcal que organiza a vida material e, em consequência, a produção ideológica, cultural e artística; logo, privilegia determinados setores. A divisão sexual do trabalho, que encerra as mulheres em funções do trabalho reprodutivo, as impediu por séculos de atuar no papel de escritoras e, a partir do século XIX, quando isso começou a mudar, "as mulheres permaneciam nas margens [que] nos condicionaram a pensar que a voz dos homens não tem gênero e por isso existiam duas categorias, a 'literatura', sem adjetivos, e a 'literatura feminina', presa a seu gueto" (DALCASTAGNÉ, 2005, p. 63).

A escola, por sua vez, chancela essa estreita perspectiva. Na verdade, a didatização da tradição literária reificada em práticas de sala de aula apenas reflete a realidade da produção e divulgação editorial vigente. A pesquisa basilar da pesquisadora Regina Dalcastagné demonstra, em números, a disparidade de produção e representação literárias na Literatura Brasileira. O Grupo de Estudos em Literatura Brasileira Contemporânea da Universidade de Brasília, coordenado por ela, analisou autores e enredos de cerca de 700 romances publicados por grandes editoras nos últimos 40 anos, encontrando a reiteração de um mesmo perfil tanto de autores quanto de personagens: brancos, homens, classe média, heterossexuais, moradores da zona central de grandes cidades (DALCASTAGNÉ, 2005; 2007; 2011). Logo, o que se apresenta como currículo escrito nas escolas (à parte das práticas docentes que ultrapassam as listas de conteúdos) é a reprodução desse padrão observado pelas diversas fases dessa pesquisa. São a essas obras que são dedicadas a maior parte dos acervos, dos estudos, e, até pouco tempo, mesmo da produção acadêmica, o que reproduz a hegemonia masculina no papel de escritor. Ilustram essa situação os seguintes casos: em 2014, a maior festa literária da América Latina, a Feira Literária de Paraty (FLIP), apresentava apenas 15\% de mesas e espaços para serem discutidas obras 
literárias escritas por mulheres ou por críticas e pesquisadoras de literatura (ROSSI, 2017); ainda hoje, apenas $13,7 \%$ dos premiados com o Nobel de Literatura são mulheres.

Por outro lado, grupos de leitura como o movimento Leia Mulheres, a crítica literária e mesmo a mídia vêm atuando no sentido de promover a leitura e o estudo de obras de autoria feminina. Atualmente, um levante relacionado a pautas políticas, epistemológicas e interculturais vem ocorrendo no sentido de colocar em prática o que vem sendo proposto, entre outros movimentos, pelos chamados Estudos Decoloniais (WALSH, 2009), que deslocam o centro dos debates culturais e políticos do sujeito "neutro" (aquele que identifica mulheres, negros e negras, povos originários e cidadãos do capitalismo periférico como "O Outro") e promovem, justamente, a autolegitimação desses "outros" sujeitos (RIBEIRO, 2019). Já em 2019, por exemplo, de acordo com o Portal G1 (2019), a autora mais vendida na FLIP foi Grada Kilomba, escritora de língua portuguesa, negra, com raízes em Angola; e dos dez livros mais vendidos na ocasião, seis foram escritos por mulheres. Logo, é nítido que há leitoras e leitores que desejam se ver representados no cenário literário local e mundial, o que muito recentemente vem transformando o mercado editorial, impulsionando obras literárias de autorias diferentes daquelas privilegiadas até o fim do século XX.

No entanto, no campus Restinga, nas ementas das disciplinas de Língua Portuguesa e Literatura, tanto dos cursos de Ensino Médio Integrado (Lazer, Eletrônica e Informática) e do Programa de Integração da Educação Profissional Técnica de Nível Médio ao Ensino Médio na Modalidade de Educação de Jovens e Adultos (Comércio e Agroecologia), quanto na Licenciatura em Letras, o elemento estruturante são os períodos literários historicizados e didatizados em que pouca diversidade de vozes se vê, ainda. Apesar das iniciativas dos/das docentes no sentido de proporcionar experiências de leitura que transcendam o currículo, ao dedicar o tempo de aula para possibilitar o contato necessário com essas obras, junto a propostas de ensino que possibilitem a produção textual e a análise linguística, muitas vezes falta tempo na disciplina de Língua Portuguesa e Literatura no Ensino Médio para lidar com obras mais contemporâneas, sejam brasileiras ou não, que privilegiem outros olhares sobre o humano, a cultura e a linguagem, como deve ser a abordagem de leitura literária como um direito, com o objetivo de ampliar nossos horizontes de vivências (CANDIDO, 1995). Por isso, salvo iniciativas individuais, acaba-se privilegiando a circulação de obras de autoria masculina, sobretudo do período anterior ao advento do Modernismo - cujo estudo ocorre, de acordo com os Projetos Pedagógicos dos Cursos, junto à literatura contemporânea no terceiro ano (na modalidade integrada) e no terceiro semestre (na modalidade PROEJA) do Ensino Médio. Logo, no nosso contexto, se seguidas as ementas, o ensino 
baseia-se majoritariamente em bibliografias cujos nomes proeminentes são os mesmos sujeitos apontados pelo grupo de Dalcastagné.

Por isso, entendemos que é necessário qualificar a experiência leitora para lidar com a diversidade de vozes e sentidos em consonância com a contemporaneidade, com que podemos nos beneficiar na nossa formação como leitores e leitoras. Daí que a promoção da leitura de obras escritas por mulheres foi o objetivo principal do projeto, atuando na ampliação dos repertórios de leitura promovidos no Campus, com o objetivo de desenvolver o letramento literário a partir de experiências de leitura mais diversas.

\section{Atividades do projeto}

Para atualizar esses objetivos na prática, desenvolvemos um questionário de diagnóstico de leitura divulgado à comunidade, promovemos a divulgação de dicas e resenhas de livros produzidas por estudantes e servidores, produzimos materiais de divulgação sobre literatura escrita por mulheres, por meio de postagens nas redes sociais e boletins informativos produzidos pelas bolsistas, e organizamos encontros para discussão de obras escolhidas.

Houve algumas mudanças das ações planejadas às realizadas devido à pandemia da COVID19. Inicialmente, planejamos usar o ambiente do campus para reunir as pessoas no intuito de debater as obras. Além disso, tínhamos como objetivo analisar o acervo da biblioteca do campus a partir de sugestões enviadas através do questionário de leitura e das dicas e resenhas produzidas pela comunidade escolar. Assim, analisaríamos a diversidade das obras e a presença da autoria feminina na seção de ficção. Devido à suspensão das atividades presenciais, não pudemos executar esse planejamento. Por isso, focamos na comunicação via redes sociais e na organização e realização de encontros virtuais. Além disso, abrimos a possibilidade de participação do público externo, de modo que tivemos a presença de membros da comunidade do bairro, de outros campi do IFRS, de outros grupos de incentivo à leitura que estabeleceram contato via redes sociais e de cursinhos pré-vestibular populares.

\subsection{Questionário: diagnóstico de leitura}

Entre nossas ações, elaboramos e enviamos um questionário para a comunidade do campus. Nosso principal objetivo era conhecer as práticas de leitura da nossa comunidade, fazer questionamentos 
que levassem a refletir sobre o tema do projeto e divulgar nossas ações. Por isso, o questionário, que foi divulgado via e-mail para servidores e estudantes, apresentava perguntas sobre frequência e quantidade de leituras, mudança de hábitos de leitura durante a pandemia, fontes de dicas de livros e questões específicas sobre obras escritas por mulheres, entre perguntas de múltipla escolha e de resposta aberta. Ao todo obtivemos 52 respostas; 31 eram estudantes do Ensino Médio Integrado, oito estudantes do Ensino Superior, sete técnicos administrativos, cinco docentes e um estudante do curso técnico subsequente.

Alguns dados nos chamaram atenção: sobre a frequência de leitura, $50 \%$ dos participantes afirmaram ter lido mais durante a pandemia e 57,6\% relataram ler entre 2 e 10 livros por ano. Esses dados fortaleceram nosso objetivo de formar uma comunidade de leitores/as, tanto no sentido de aproximar a comunidade que já é leitora, quanto no sentido de promover ainda mais a leitura de textos literários. À pergunta "Como você escolhe obras para ler?", 63,5\% responderam que escolhem por indicações de amigos, $51,9 \%$ por dicas nas redes sociais e 42,4\% por indicação de professores. Esse dado também nos apontou que os ambientes virtuais são um dos caminhos mais trilhados para chegar a obras literárias; portanto, nos motivou a continuar promovendo dicas e resenhas escritas pela comunidade escolar nas redes sociais.

Das perguntas que enfocavam diretamente o objetivo do nosso projeto, duas delas apresentaram resultados que nos interessaram particularmente. À pergunta "Se você retirasse da sua estante todos os livros escritos por homens, deixando apenas os livros escritos por mulheres, quantos você acha que sobrariam?", 62\% responderam que sobraria um quarto ou menos. Já à pergunta "Você já foi à biblioteca do campus e não se sentiu contemplado/a com o acervo de literatura escrita por mulheres?", 42,3\% responderam sentir falta de mais autoras no acervo da biblioteca do campus Restinga, que citaram diretamente na pergunta seguinte. Esses dados corroboraram nossa justificativa de ações, uma vez que, convidada a refletir sobre o tema, a própria comunidade escolar percebe essa lacuna tanto em sua trajetória pessoal de leitor/a quanto no espaço escolar.

\subsection{Dicas de livros e resenhas}

Desde 0 início do projeto, convidamos, por e-mail, todos aqueles interessados em literatura a enviar dicas de leitura contendo um breve resumo do livro e os motivos pelos quais a obra havia marcado a trajetória do leitor. Posteriormente, criamos um formulário para envio das dicas e abrimos a possibilidade de enviar textos mais longos, no formato de resenhas. A partir disso, as bolsistas criaram 
cards de divulgação e publicaram os textos nas redes sociais do projeto. Ao todo, recebemos 18 dicas de resenhas de livros; quatro escritas por estudantes do Ensino Superior, outras quatro por docentes, seis por estudantes do Ensino Médio, dois por técnicos educacionais, um pelo Núcleo de Estudos AfroBrasileiros e Indígenas e um por membro externo da comunidade.

Avaliamos que essa ação foi bastante proveitosa, uma vez que houve envolvimento de todos os segmentos da comunidade escolar, e a diversidade de gêneros, autoras e temáticas nos proporcionou também conhecer mais de perto as práticas de leitura do público do projeto. Além disso, considerando as respostas ao questionário aplicado, consideramos que, nesse momento de atividades remotas, as redes sociais têm sido cruciais para proporcionar diálogos e trocas entre estudantes, professores, técnicos e comunidade externa. No nosso grupo, por exemplo, temos uma bolsista que conheceu 0 projeto através das redes, leu uma resenha de uma colega e buscou a leitura da obra indicada. Sua participação na promoção das atividades do projeto se deve, portanto, a esse importante meio de comunicação e disseminação de saberes.

\subsection{Encontros de discussão}

Consideramos que a literatura "é uma experiência a ser realizada" (COSSON, 2012, p. 17). Desse modo, ensinar literatura pressupõe proporcionar a leitura mediada, e, por isso, não pode se encerrar em aulas expositivas ou listagem de conhecimentos enciclopédicos sobre obras ou sobre períodos literários e autores. Entendemos que é tarefa da escola desenvolver o letramento literário, entendido como "estado ou condição de quem não apenas é capaz de ler o texto em verso e prosa, mas dele se apropriar efetivamente por meio da experiência estética, saindo da condição de mero expectador para a de leitor literário" (SILVA; SILVEIRA, 2013, p. 96).

Logo, a atividade principal do nosso projeto foi a promoção de encontros de discussão de obras, com o objetivo de proporcionar momentos de construção coletiva dessa experiência. Nos envolvemos na seleção, leitura e discussão interna sobre romances. Nesses encontros internos, que chamamos de encontros de organização, sugerimos obras, escolhemos critérios, tomamos decisões; elencamos sensações de leitura, elementos do enredo, relações intertextuais, funcionamento da linguagem, elementos biográficos das autoras e características do contexto histórico de produção. Escolhemos chaves de debate para apresentar a obra e expor nos encontros, a partir de um olhar coletivamente construído, buscando compartilhar nossas próprias experiências de leituras literárias e fomentar a 
discussão entre o público presente. Em suma, buscamos atualizar na prática um círculo de leitura, a partir da concepção de que

\begin{abstract}
círculos de leitura são espaços sociais nos quais as relações entre textos e leitores, entre leitura e literatura, entre o privado e o coletivo são expostas e os sentidos dados ao mundo são discutidos e reconstruídos. Participar de um círculo de leitura é compartilhar com um grupo de pessoas as interpretações dos textos com as quais construímos nossas identidades e da sociedade em que vivemos (COSSON, 2020, p.154).
\end{abstract}

Para isso, nos reunimos virtualmente toda semana para escolher e debater obras e organizar os encontros abertos. Esses encontros aconteceram via Google Meet, no período da noite, e a inscrição foi feita via formulário. Divulgamos os eventos buscando interagir com o público nas redes sociais e via email institucional, criando cards de "mistério" e dicas sobre as obras e as autoras para instigar a participação e, então, divulgar os dados básicos sobre a obra escolhida e a autoria com antecedência para possibilitar a leitura. Os encontros, de modo geral, tiveram entre trinta e quarenta pessoas inscritas e tivemos efetivamente entre vinte e trinta participantes em cada um.

\title{
3.2.1 Debatendo Ponciá Vicêncio, de Conceição Evaristo
}

Assim, chegamos ao primeiro encontro aberto do grupo Leia + Mulheres Restinga, que aconteceu em outubro de 2020, pensado e preparado por várias semanas pela equipe do projeto. Essa primeira reunião, tal como as seguintes, contou com a comunidade escolar (estudantes, docentes e técnicos) e também com pessoas da comunidade externa.

Escolhemos começar com a autora brasileira Conceição Evaristo, que conta com uma vasta produção literária, entre artigos, coletâneas de poemas, livros de contos e romances. Atualmente, é uma escritora bastante celebrada: foi indicada para a Academia Brasileira de Letras; foi a patrona de diversas feiras do livro e da Olimpíada de Língua Portuguesa Escrevendo o Futuro; recebeu diversos prêmios e passou a ser lida nos contextos escolares. Optamos pelo romance contemporâneo Ponciá Vicêncio (EVARISTO, 2017) que é considerado um romance de aprendizagem: aquele onde o processo de desenvolvimento do personagem é exposto desde a infância ou adolescência até a vida adulta. É um romance circular, de modo que a história começa e termina no mesmo ponto.

Um ponto decisivo para essa escolha foi o interesse nessa obra demonstrado no questionário respondido anteriormente, já que foi solicitada como leitura obrigatória no vestibular da Universidade Federal do Rio Grande do Sul em 2020, o que também havia acontecido no vestibular do ano anterior. Após os debates internos, em várias etapas, fizemos um recorte dos pontos principais da obra, para 
depois prepararmos o material de apresentação ao público do encontro. Isso se deu através de uma sinopse bem detalhada do livro, junto a elementos que nos chamaram a atenção durante a interpretação que desenvolvemos conjuntamente. Em seguida, o público presente foi convidado a dar sua impressão sobre a obra, de modo que o debate foi mediado pelo grupo.

Observamos, durante o debate, que a obra de Conceição nos revela uma subjetividade sofrida e intimista, com um narrador onisciente que se preocupa em demonstrar as emoções da personagem principal e sua perspectiva. Ponciá Vicêncio é um romance intrigante que tem um final inesperado e nos mostra, na escrita da autora, sua visão tão comentada no meio acadêmico sobre a escrevivência: a narrativa fictícia é construída com verossimilhança e calcada em uma espécie de experiência coletiva das mulheres negras. Esse foi um dos pontos-chave do debate. Outro aspecto observado durante 0 encontro aberto foi a presença de uma protagonista feminina complexa, que tem momentos muito diversos durante a narrativa: é capaz de entrar em si mesma e ao mesmo tempo tem coragem de pôr em prática seus planos, mesmo sem saber ao certo como irá realizá-los. O romance acompanha os frequentes momentos de introspecção e de acesso à memória da protagonista, e o discurso indireto livre nos guia, na narrativa, por essa vida interna.

No encontro, propusemos como chave para o debate questões relacionadas à raça, território, gênero, sociedade e memória. Elementos do enredo nos levaram a debater a violência doméstica, a representação literária das masculinidades e o importante papel da ancestralidade, ponto crucial para compreensão da estruturação da narrativa: encontramos na herança de Ponciá uma verdadeira incógnita com relação aos seus antepassados, que vai se desenvolvendo ao longo da história. Além disso, as relações com o sagrado e com o mistério se apresentam no romance, por exemplo, através da figura da personagem Nengua Kainda, a anciã da vila que costumava adivinhar o futuro e dar conselhos a todos. Discutimos também sobre relações de poder através do personagem Luandi, irmão de Ponciá, que se admirava com o fato de ter encontrado um policial negro na cidade grande e por isso queria ter essa mesma autoridade.

Nesse encontro, tínhamos como objetivo promover a obra de Conceição Evaristo, além de promover um espaço de discussão em consonância com o desejo dos estudantes do Ensino Médio relacionado a essa leitura obrigatória do vestibular. Ao final do encontro, avaliamos que o debate, tanto em termos da forma estética quanto da quantidade de temas relevantes para a comunidade trazidos pelo público (identidades negras na literatura, memória, ancestralidade, pobreza e violência) foi muito construtivo em termos de proporcionar uma interação real com a obra da autora. 


\subsubsection{Debatendo obras de distopia e ficção científica}

No mês seguinte, organizamos o segundo encontro virtual, enfocando gêneros literários pouco usuais quando se trata de literatura na escola: ficção científica e distopias. Entendemos que uma obra de fiç̧ão cientifica, de terror ou distopia consegue representar realidades que nunca seríamos capazes de imaginar e, ao mesmo tempo, convida a repensar nossa própria realidade. Para isso, iniciamos a leitura de três obras. A primeira foi Frankenstein ou o Prometeu Moderno, de Mary Shelley (SHELLEY, 2017), romance de terror gótico, publicado pela primeira vez em 1818. A escolha foi guiada pelo desejo de proporcionar contato com essa obra fundante da ficção científica. A segunda foi O Conto da Aia, de Margaret Atwood (ATWOOD, 2017), romance distópico da autora canadense, que revela uma teonomia totalitária fundamentalista cristã, escrito em 1985, com várias premiações e adaptação recente para 0 audiovisual. Acreditamos que essa relação intertextual com a adaptação para série televisiva de sucesso pode ser um gatilho para o interesse na leitura das obras. E o terceiro foi o romance histórico Kindred: Laços de Sangue (BUTLER, 2019) que incorpora viagens no tempo e narrativas sobre a escravidão, da autora norte-americana Octavia Butler, publicado pela primeira vez em 1979. Descobrimos essa autora por meio de pesquisas; ela é considerada a "rainha da ficção científica" nos Estados Unidos, sendo também um best-seller em um gênero que, embora as mulheres tenham papel fundamental, como vimos através da história de Mary Shelley, muitas vezes têm pouco destaque. Apesar de diversos entre si, todos trazem o elemento do fantástico ou de "mundos possíveis", o que acreditamos que proporciona, ao mesmo tempo, distância da realidade e inevitáveis paralelos com o contexto atual. Além da fantasia, motes como questões de gênero, raça, relações de poder, abuso sexual, subjugação e vaidade são algumas temáticas em comum que pudemos verificar nessas obras.

Frankenstein, por exemplo, nos chamou atenção pelo fato da autora ter sido a pioneira no gênero; ela tinha 19 anos quando escreveu a obra e não podia usar seu próprio nome na autoria, usava o nome do marido. Observamos que, embora a figura do monstro de Shelley seja comum na cultura de massas, o próprio Frankenstein, que é o nome do cientista criador, é confundido sempre com a criatura. Durante 0 debate, o romance epistolar proporcionou reflexões profundas sobre quem era realmente 0 monstro na história.

Já O Conto da Aia se tornou famoso após o lançamento da série de televisão em abril de 2017. Através dessa obra, uma das bolsistas propôs um paralelo com a realidade atual no Irã, onde desde 1980 as mulheres são subjugadas e tiveram seus direitos básicos de liberdade interditados. Entre outros 
elementos trazidos pela discussão, o público estabeleceu relações com a sociedade brasileira sob o governo atual, na figura da Ministra dos Direitos Humanos.

Por último, ao longo da discussão de Kindred, foram debatidos temas relacionados à escravidão, já que Dana, protagonista da história, vive entre viagens no tempo que a levam de 1976 a um período anterior ao início da guerra civil americana. O livro tem como pano de fundo a escravidão e Dana se vê nesse ambiente onde tenta se defender para sobreviver, afinal ela é uma mulher negra em uma época muito hostil, de modo que a obra nos faz refletir sobre a situação passada do escravagismo e seus reflexos no mundo contemporâneo, como estratégias de resistência, relações inter-raciais, a origem da miscigenação e a romantização da violência sexual como raiz da pretensa democracia racial. Durante o debate, foi levantado o fato de como questões antigas como a posse do corpo negro ainda repercutem nos abusos dos corpos das mulheres no mundo contemporâneo.

A ideia desse encontro com mais de uma obra a ser discutida tinha como objetivo proporcionar trocas entre leitores das diferentes obras, fazer relações intertextuais e incentivar a leitura dessas escritoras tão diferentes. Avaliamos ao final do encontro que, embora tenha havido pouco tempo para discussão mais detalhada de cada obra, o encontro foi positivo, no sentido de proporcionar diálogos entre leitores/as que têm afinidade com esses gêneros literários.

\subsubsection{Debatendo Bom dia, Verônica}

Para pensar a temática do terceiro encontro, solicitamos que o público participante no segundo encontro listasse temáticas e gêneros que gostariam de ver tratados pelo grupo. Um dois mais votados foi suspense. Por isso, pesquisamos livros e autoras e decidimos propor a leitura do best-seller Bom dia, Verônica, um suspense policial publicado em 2016 sob pseudônimo Andréia Killmore (KILLMORE, 2016). O pseudônimo foi deixado de lado no ano de 2020, quando os autores revelaram suas identidades. $O$ livro foi escrito de maneira colaborativa entre dois autores, llana Casoy e Raphael Montes, dois grandes nomes dentro do gênero de suspense e literatura criminal no Brasil. llana tem diversos livros famosos no Brasil, destacando-se $O$ caso Nardoni e $O$ quinto mandamento, que tratam de casos policiais que chocaram o país. Já Raphael Montes atua na área da ficção de suspense, tendo também vários outros sucessos publicados no Brasil.

O livro apresenta temas como violência contra a mulher, assassinato em série, investigação policial e muito suspense. Verônica é uma policial que trabalha como escrivã na delegacia de homicídios, é uma mulher corajosa com uma sede de justiça inesgotável. Ela não aguenta ver as injustiças dentro 
da delegacia, especialmente contra as mulheres, e decide investigar e resolver casos por conta própria. A obra nos convida a refletir sobre o machismo e a misoginia dentro da nossa sociedade, além de trazer questões como sororidade e protagonismo feminino.

Ao longo do encontro, houve muitos comentários sobre o enredo e as sensações de leitura e muitas pessoas se posicionaram. Um dos pontos mais debatidos da obra foi a personagem Verônica, a protagonista. Os participantes ficaram divididos: alguns não gostaram e se sentiram incomodados com o comportamento da Verônica de agir sozinha, não procurar ajuda nunca, agir como o grande herói, um comportamento comum em várias personagens masculinas, mas que causou estranhamento vindo de uma personagem feminina. Já outros participantes gostaram da construção da personagem justamente por isso, por ela fazer esse papel que é muitas vezes considerado como masculino.

Outro ponto que gerou muitas reflexões foram as comparações entre a série e o livro na representação da personagem Janete, esposa do serial killer Brandão. Muitos participantes tinham dúvidas sobre a personalidade dela, que muitas vezes na série parece passiva, e até "feliz" com a situação de violência em que se encontra. Porém, ao fazer uma comparação com o livro, essas características se mostraram inverídicas, pois a personagem é muito ativa e inteligente na obra original. Nessa discussão, foram levantados temas como os relacionamentos abusivos e o ciclo da violência contra a mulher, além da representação de personagens femininas nas produções televisivas.

Como resultado da discussão, avaliamos que instigamos muitas reflexões, mas também fomos instigadas enquanto equipe pelos participantes, que trouxeram interpretações e posicionamentos muito interessantes - até mesmo divergentes. Também analisamos e compreendemos em conjunto a complexidade e a importância das personagens femininas dentro e fora do romance. Além disso, recebemos muitas indicações de obras e elogios sobre o desenvolvimento do projeto. Nesse último encontro, percebemos que o vínculo com a comunidade tem ficado cada vez mais forte. Foi o encontro com o maior índice de participação, envolvendo participantes que nunca haviam se manifestado, como estudantes da Educação de Jovens e Adultos. É notório que, ao longo do tempo, a comunidade foi se familiarizando e se sentindo mais à vontade com o projeto e a equipe. Foram 30 participantes presentes no dia, e em vários momentos tivemos uma "fila" virtual de pessoas querendo falar sobre seu ponto de vista.

\section{Considerações finais}

Cosson (2017) afirma que a análise literária deve conceber a literatura como um processo de comunicação, de modo que o desenvolvimento das competências e habilidades relacionadas à leitura 
literária precisa demandar respostas de quem lê e funcionar como um convite a penetrar de diferentes formas na obra e explorá-la sob os mais diversos aspectos. Nesse sentido, avaliamos que a nossa proposta de ações de ensino, primeiro de aproximação e comunicação, através do questionário de leitura e das dicas e resenhas, depois culminando nos encontros de discussão atingiram seus objetivos de promover o letramento literário, isto é, proporcionar momentos de interação cujo centro é o texto literário. Além disso, a pesquisa por autoras e o debate de obras tão diferentes entre si foram positivas no sentido de diversificar as mediações de leitura que a escola oferece. Ademais, a recorrente análise crítica de elementos relacionados ao cotidiano e à vivência da mulher na sociedade contemporânea confirmou 0 potencial de ampliação de temas que a abordagem a obras de origens e gêneros diversos pode proporcionar.

Refletindo sobre os efeitos do projeto, concordamos que "no texto literário encontramos o senso de nós mesmos e da comunidade a que pertencemos" (COSSON, 2017, p. 17). Acreditamos que criamos uma comunidade de leitoras entre as organizadoras do projeto. Sem dúvida o protagonismo das estudantes bolsistas foi revelando um desenvolvimento crescente de suas próprias ferramentas de leitura, interpretação e compreensão. Esse processo permitiu qualificar não só a formação dessas estudantes, mas também o impulsionamento da comunidade escolar para estabelecer esse círculo de leitores nos encontros abertos. Isso se manifestou por meio do número crescente de vozes tomando turnos ao longo dos encontros. Por meio do compartilhamento das impressões de leitura em relação a elementos estéticos e aos temas presentes nas obras, por meio de questionamentos, de comentários sobre as relações entre literatura e realidade e do diálogo entre opiniões diferentes se constituiu um círculo de leitores; de fato, uma comunidade leitora.

\section{Referências}

ATWOOD, M. O conto da aia. Rio de Janeiro: Rocco, 2017.

BORDIEU, P. Las reglas de las artes. Gênesis y estructura del campo literario. Barcelona: Anagrama, 2005.

BUTLER, O. E. Kindred: Laços de Sangue. São Paulo: Editora Morro Branco, 2019.

CANDIDO, A. O direito à literatura. In: Vários escritos: Edição revista e ampliada. São Paulo: Duas Cidades, 1995.

COSSON, R. Letramento Literário: teoria e prática. $2^{\mathrm{a}}$ ed. $2^{\mathrm{a}}$ reimpressão, São Paulo: Contexto, 2012. . Círculos de leitura e letramento literário. São Paulo: Contexto, 2020. 
DALCASTAGNE, R. A personagem do romance brasileiro contemporâneo. Estudos De Literatura Brasileira Contemporânea, v. 26, 2011, p. 13-71.

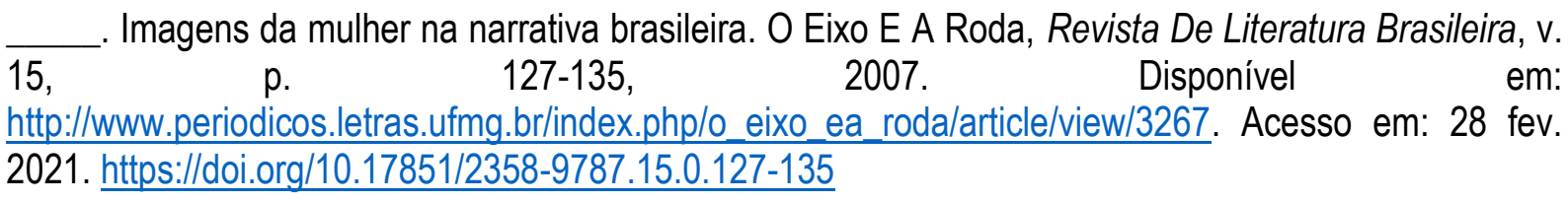

. A personagem do romance brasileiro contemporâneo 1990-2004. Estudos de Literatura Brasileira

Contemporânea, n. 26, p. 13-72, 2005. Disponível em: https://periodicos.unb.br/index.php/estudos/article/view/9077. Acesso em: 28 fev. 2021.

EVARISTO, C. Ponciá Vicêncio. Rio de Janeiro: Pallas, 2017.

Grada Kilomba é autora mais vendida da Flip 2019. G1, 14 de set. de 2019. Disponível em: https://g1.globo.com/pop-arte/noticia/2019/07/14/grada-kilomba-e-autora-mais-vendida-da-flip-2019veja-o-top-10.ghtml. Acesso em: 10 mar. 2021.

KILLMORE, A. Bom dia, Verônica. Rio de Janeiro: DarkSide Books, 2016.

MEDEIROS, V. L. C. Diversidade Intercultural e leitura literária na educação básica na perspectiva do pensar decolonial. In: TETTAMANZY, A. L. L.; SANTOS, C. M. (Orgs.). Lugares de fala, lugares de escuta nas literaturas africanas, ameríndias e brasileira. Porto Alegre: ZOUK, 2018.

ROSA, S. Ri. C. Um olhar sobre o romance Úrsula, de Maria Firmina dos Reis. LiterAfro - Portal de Literatura Afro-Brasileira da UFMG. Disponível em: http://www.letras.ufmg.br/literafro/autoras/29-criticade-autores-feminios/321-um-olhar-sobre-o-romance-ursula-de-maria-firmina-dos-reis-critica. $\quad$ Acesso em: 15 fev. de 2020.

ROSSI, J. S.; DUTRA, L. Práticas de leitura compartilhada nos clubes Leia Mulheres: estudo exploratório com mediadoras de leitura. Anais do $43^{\circ}$ Congresso Brasileiro de Ciências da Comunicação, 2020, p.115. Disponivel em: http://www.intercom.org.br/sis/eventos/2020/resumos/R15-0752-1.pdf. Acesso em: 10 mar. 2021.

ROSSI, M. A Flip paga sua dívida com as mulheres. El País, São Paulo, 25 de julho de 2017. Disponível em: https://brasil.elpais.com/brasil/2017/07/21/cultura/1500669600_382468.html. Acesso em: 10 mar. 2021.

SANTOS. J. G. P. Leia Mulheres: leitura literária e ressignificação da subjetividade feminina. Anais do XVIII Seminário Internacional Mulher e Literatura. p. 486-393. 2019 Disponível em: https://editoracriacao.com.br/wp-content/uploads/2019/12/mulhersite.pdf. Acesso em: 10 mar. 2021.

SILVA, A. M. de O. C.; SILVEIRA, M. I. M. Letramento Literário: desafios e possibilidades na formação de leitores. Revista Eletrônica de Educação de Alagoas, v. 1, n. 1, 2013, p. 92-101. Disponível em: http://www.educacao.al.gov.br/reduc/edicoes/1a-edicao/artigos/reduc-1a-. Acesso em: 15 fev. De 2020.

SHELLEY, M. Frankenstein ou o Prometeu Moderno. Rio de Janeiro: DarkSide Books, 2017. 
WALSH, C. Interculturalidade crítica e pedagogia decolonial: in-surgir, re-existir e re-viver. In: CANDAU, V. M. (org.) Educação intercultural na América Latina: entre concepções, tensões e propostas. Rio de Janeiro: 7Letras, 2009.

Data de submissão: 15/03/2021. Data de aprovação: 13/04/2021. 